\title{
Bond Strength Of Different Artificial Tooth Manufacturing To Microwave Cured Acrylic Denture Base
}

Nadira A Hatim

BDS, MSc (Assist Prof)

Radhwan H Hasan

BDS, MSc (Lect)
Department of Prosthetic Dentistry

College of Dentistry, University of Mosul

$$
\begin{aligned}
& \text { الملاصة. }
\end{aligned}
$$

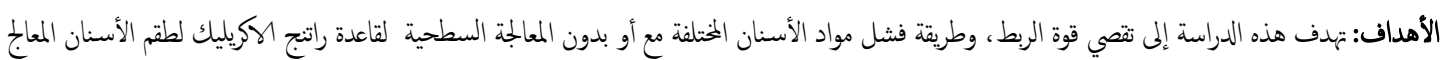

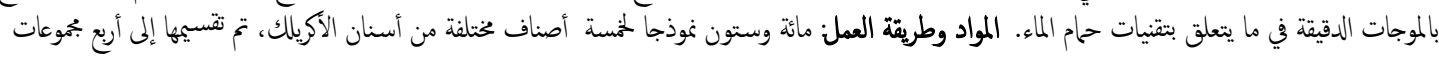

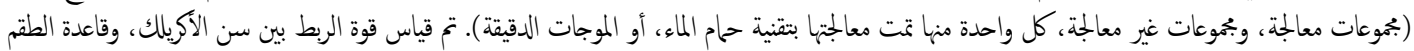

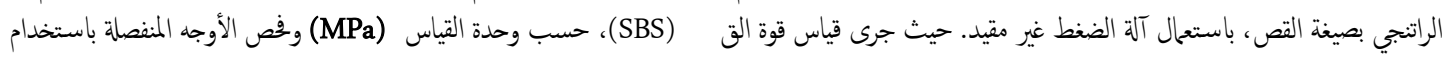

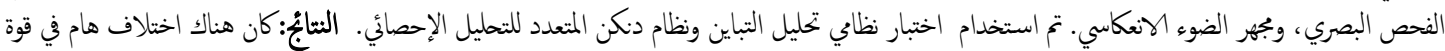

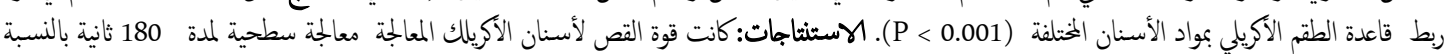

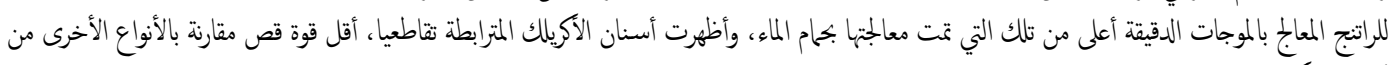

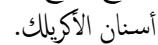

$$
\begin{aligned}
& \text { الكلمات المثتاحية: الموجات الدقيقة، قوة الربط، أسنان الاكريلك المعالجة }
\end{aligned}
$$

\begin{abstract}
AIMS of this study are to investigate the bond strength and mode of failure of different tooth materials with and without surface treatment to acrylic resin denture base cured by microwave in relation to water bath techniques. MATERIALS AND METHODS: One hundred sixty samples of five different brands of acrylic teeth were divided into four groups (untreated and treated groups each of these were cured by water bath or microwave techniques). The bond strength between acrylic tooth and denture base resin was measured in shear mode by using unconfined compression machine. The shear bond strength (SBS) in MPa was calculated, debonded surfaces were examined using visual examination and reflecting light microscope. Analysis of variance (ANOVA) and Duncan's multiple range tests were used for statistical analysis. RESULTS: there was a significant difference in bond strength of acrylic denture base to different tooth materials $(\mathrm{P}<0.001)$. CONCLUSIONS: SBS of acrylic teeth treated by monomer surface treatment for 180 seconds to microwave cured resin was significantly higher than that of water - bath cured resin, and cross - linked acrylic teeth showed lowest SBS compared to other type of acrylic teeth.
\end{abstract}

Key words: Microwave, Bond strength, Cross - linked acrylic teeth.

HatimNA, HasanRH. Bond Strength Of Different Artificial Tooth Manufacturing To Microwave Cured Acrylic Denture Base. Al-Rafidain Dent J. 2010; 10(1): 8-16

Received: $24 / 2 / 2008 \quad$ Sent to Referees: $26 / 2 / 2008$

Accepted for Publication: 20/4/2008

\section{INTRODUCTION}

One of the primary advantages of acrylic teeth is their ability to bond chemically to the denture base resin, thereby providing better retention than that obtained by the mechanical bonding of porcelain teeth. Occasionally, failures have been observed in which plastic (acrylic) teeth break loose from denture, indicating that chemical bonding does not always occur $^{(1,2,3)}$.

Bond of acrylic teeth should occur with denture base if the acrylic resin teeth are clean since the presence of, a thin film of grease, wax or separating medium on the hard resin surface is sufficient to pre- 
vent any chemical union.

across the joint ${ }^{(4,5,6)}$. The resin dough does not polymerize too rapidly after contact with the acrylic resin teeth ${ }^{(7)}$, availability of the monomer ${ }^{(8)}$. The tooth is not too highly cross-linked ${ }^{(9)}$, and maximizing the extension of the polymerization surface through a large surface area of tooth $^{(10)}$.

Polyzois and Dahl ${ }^{(11)}$ evaluated the bonding between acrylic resin teeth and acrylic denture base material cured by microwave, and hot water bath-technique. Superior bonding found after hot water bath-curing. While the others ${ }^{(12)}$ found that acrylic teeth with microwave-cured PMMA demonstrated significantly higher bond strengths than acrylic teeth with conventional cured PMMA, and priming of the denture tooth surface with monomer liquid yielded significantly higher bond strength than other surface treatments.

Cunningham and Benington ${ }^{(6)}$ showed that there is a need for further investigation of denture tooth de-bonding and for the development of a standardized technique to provide satisfactory denture tooth bonding.

The aims of this study are to investigate the effect of curing techniques (water bath and microwave), Surface treatment of the joint surface of acrylic teeth with methyl methacrylate "monomer" on the shear bond strength and mode of failure of ac- rylic teeth to acrylic denture base material

\section{MATERIALS AND METHODS}

One hundred sixty upper right central incisors acrylic teeth (Abdul-Nour, SuprCryl, Flori-Dent, Major-Dent and SuperLux) were selected. Care was taken to ensure that they were of standard mold with regard to size and shape. These acrylic central incisors were divided into two main groups (water bath, and microwave curing techniques), then subdivided into two subgroups (treated and untreated surface with monomer for 180 seconds before packing) ${ }^{(13)}$. Each subgroup was divided into five groups (8 samples) of each type of tooth material.

Preparation of Samples: A rubber mold of casting ring was used to prepare (round form) stone bases (13 mm. thicknesses, $65 \mathrm{~mm}$. diameter). By using surveyor, the rubber mold was fixed in a position parallel to the horizontal plane (zero plane). Dental stone was mixed according to manufacturer's instructions and poured to fill the rubber mold. About $4 \mathrm{~mm}$ of the incisal portion of each central incisor was embedded in the stone mixture, only ridge lap portion appears out of the stone mixture (Figure 1).

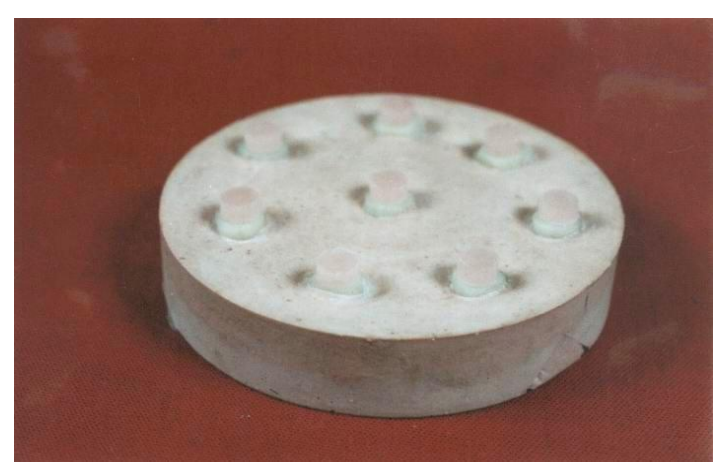

Figure (1): Stone base with 8 ridge lap portion of acrylic teeth.

One tooth was placed at the center, and seven teeth at the periphery of the mold with $10 \mathrm{~mm}$ spaces from each other and $7 \mathrm{~mm}$. medial to the edge of the mold for each material of teeth. Each stone base was labeled.

A grasping unit was designed and manufactured specially for this study for holding the hand piece by the surveyor (Figure 2). 


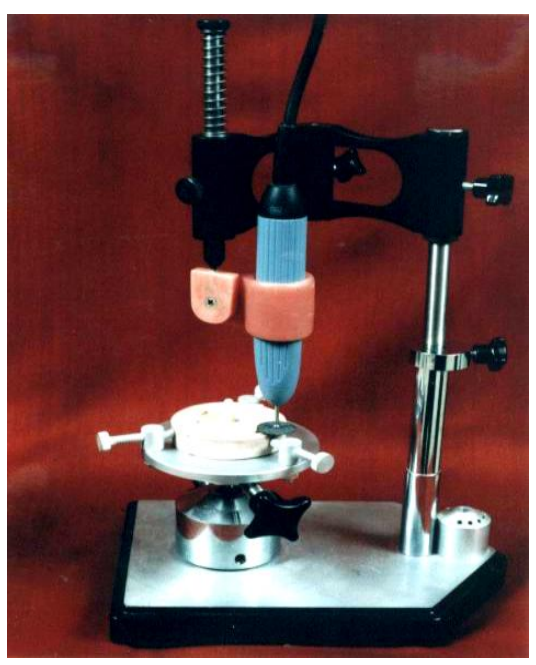

Figure (2) Mounting of 8 acrylic teeth in the stone mixture by the use of surveyor.

A constant speed $(40000 \mathrm{rpm})$ was used for cutting ridge lap by using carborandom disk for each tooth, and in one way direction.

A silicon rubber mold was specially designed for this study to prepare a wax pattern of $5 \mathrm{~mm}$ diameter and $2.5 \mathrm{~mm}$ thickness that represents thickness of denture base (ADA specification No. 12, $1975)^{(14)}$ on the prepared flat tooth surface (Figure 1). Conventional Water-Bath Curing of two steps $\left(70{ }^{\circ} \mathrm{C}\right.$ for 30 minutes, then proceed at $100{ }^{\circ} \mathrm{C}$ for 30 minutes) polymerization was used according to the manufacturer's instructions.

Microwave Curing Technique: After the investment set, the flask (FRP) ${ }^{(15)}$ was placed in the microwave oven. To soften the wax, it was microwaved for 1 minute at high setting (500 watts). Then, the flask was opened and flushes both parts thoroughly with boiling water and detergent. For curing of acrylic resin, the FRP flask was placed in the microwave oven for 30 minutes at the low setting ( 80 watts), 15 minutes per side, followed by $1 \frac{1 / 2}{2}$ minutes at the high setting (500 watts); then the flask was left aside for slow bench cooling before opening. The samples were stored for 7 days in distilled water $\left(37 \pm 1{ }^{\circ} \mathrm{C}\right)$ in an incubator (Memmert $\mathrm{GmbH}+\mathrm{Co} \mathrm{KG}$, Germany).
Shear Bond Strength and Mode of Failure Test: After storage, all samples were embedded in cylindrical plastic rings (height $24 \mathrm{~mm}$, diameter $20 \mathrm{~mm}$ ), and fixed on the glass slide by a soft wax. The glass slide placed on the surveyor table. The PMMA part of the sample was attached to the analyzing rod by soft wax; to ensure its parallelism, then the sample inserted carefully into the plastic ring until the tooth-PMMA interface was flush with the edge of the plastic ring then the surveyor arm fixed at this position. A soft mixture of auto polymerizing acrylic resin was poured around the acrylic tooth. The bond strength between acrylic tooth and PMMA base was measured in shear mode by using compression machine (Unconfined Compression Machine, Soil Inc., Model CN 472, EVANSTON, Ill. U.S.A) at cross head speed of $1 \mathrm{~mm}$ per minute. The samples were held in a metal fixture (grasping unit), manufactured especially for this study and the test holder was oriented in such a manner that the cross head applied a force parallel to the bonding surface of the acrylic resin denture tooth. The shear load was applied with a knife-edged rod (manufactured by computerized milling machine) positioned at the base of the bonded PMMA base (Figure $3)$. 


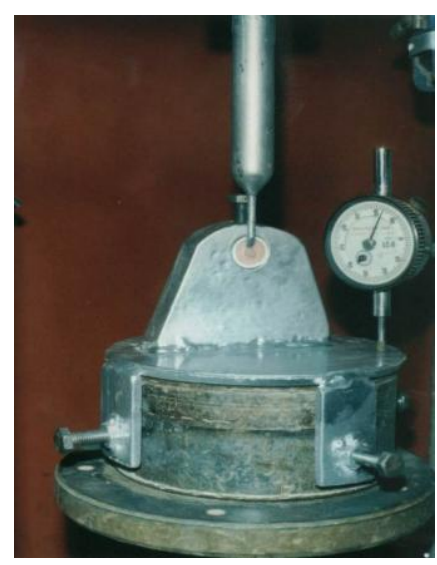

Figure (3) Grasping unit and a knife-edged rod positioned at the base of the bounded PMMA base

The bond strength (B) in MPa was calculated based on the load $(\mathrm{F})$ in $(\mathrm{N})$ at fracture and adhesive surface area $(\mathrm{S})$ in $\mathrm{mm}^{2(16 .)}$.

\section{$\mathrm{B}(\mathrm{MPa})=\mathrm{F} / \mathrm{S}$}

The fracture site on the samples was tested by using visual examination and a reflecting light microscope $(\times 30$ magnifications). Different types of fractures were noticed and the samples were grouped accordingly.

Analysis of variance (ANOVA) test was conducted in order to show if there are significant differences among groups $(p \leq$ 0.005). Duncan's multiple range test is performed in order to compare between significant groups.

\section{RESULTS AND DISCUSSION}

The Effect of Curing Technique: The results of this study showed that SBS of acrylic teeth to microwave cured denture base resin is significantly higher than that of acrylic teeth to water bath cured denture base resin (Figure 4 ,and 5), and table (1) .

\section{圈 Untreated $\square$ Treated}

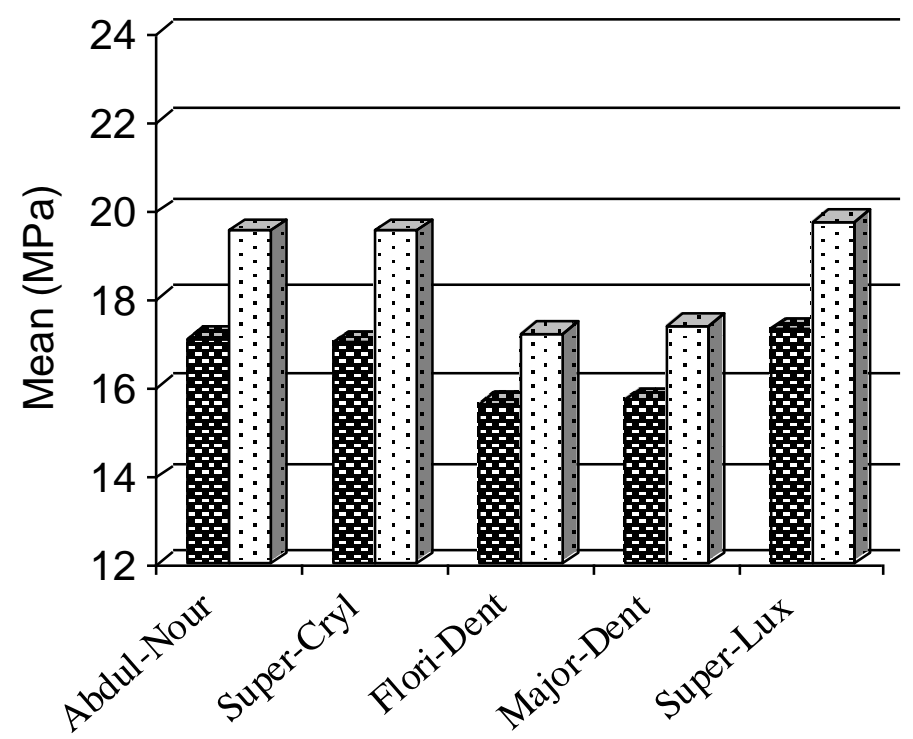

Figure (4) Means of SBS for untreated and treated acrylic teeth cured by water bath techni que. 


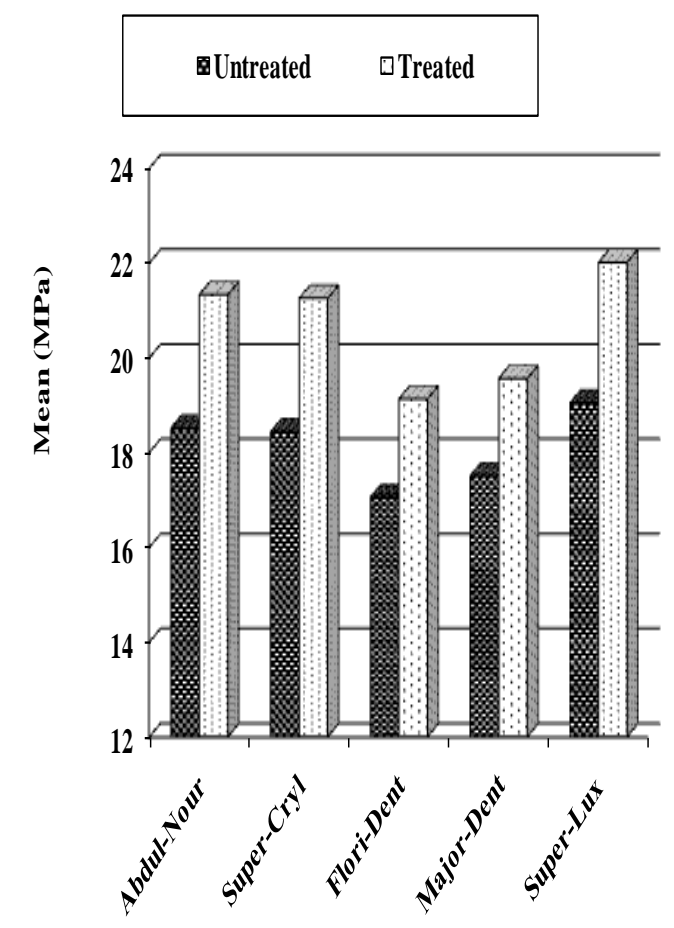

Figure (5) Means of SBS for untreated and treated acrylic teeth cured by microwave technique.

These results are supported by some authors ${ }^{(17,18)}$ reported that the bond strength of acrylic teeth to denture base resin is due to the diffusion and polymerization of monomer across the tooth base interface to form interpenetrating polymer networks. The efficiency of the attainment of such a bond depends primarily on the rate at which monomer diffuses from the base resin mixture. Higher diffusion rates of the monomer of the denture base polymer mixture into the acrylic resin polymer teeth is achieved with increasing polymerization temperature ${ }^{(16)}$.

However, microwave heating is energy conversion and not conduction heating as in a conventional water bath technique. So in microwave heating the resin absorbs energy and converts it to a local heat, raising the temperature of the resin quicker and higher than that of the conventional water bath technique ${ }^{(19,20)}$.

The Effect of Surface Treatment with Monomer: The results of this study show that treatment of the joint surface of acrylic teeth with monomer for 180 seconds before packing significantly improved its bond strength (Table 1). 
Table (1): Analysis of variance (ANOVA) test for levels of curing technique, surface treatment, type of acrylic teeth and their interactions.

\begin{tabular}{cccccc}
\hline Source of Variance & DF & Sum of Squares & Mean Square & F-value & p \\
\hline Curing Technique & 1 & 125.14 & 125.14 & 2010.7 & $0.0001^{*}$ \\
Surface Treatment & 1 & 219.72 & 219.72 & 3530.5 & $0.0001^{*}$ \\
Type of Acrylic Teeth & 4 & 134.33 & 33.58 & 539.58 & $0.0001^{*}$ \\
Curing Technique $\times$ Surface Treatment & 1 & 1.68 & 1.68 & 27.01 & $0.0001^{*}$ \\
Curing Technique $\times$ Type of Acrylic Teeth & 4 & 1.37 & 0.34 & 5.50 & $0.0004^{*}$ \\
Surface Treatment $\times$ Type of Acrylic Teeth & 4 & 6.47 & 1.62 & 26.00 & $0.0001^{*}$ \\
Curing Technique $\times$ Surface Treatment $\times$ Type & 4 & 0.07 & 0.02 & 0.30 & 0.8784 \\
$\quad$ of Acrylic Teeth & & & & & \\
$\quad$ Error & 140 & 8.71 & 0.06 & & \\
Corrected Total & 159 & 497.50 & & &
\end{tabular}

* Highly significant $\quad \mathrm{DF}=$ Degree of freedom

The mean SBS of the (80) treated samples (19.67 MPa) is significantly higher than mean SBS of the (80) untreated samples (17.32 $\mathrm{MPa}$ ) figures $(4,5)$. Monomer applied to tooth surface before packing provides a solvent effect on the tooth surface which favors a more effective diffusion of the monomer of the denture base polymer across the tooth denture base interface to form interpenetrating polymer networks ${ }^{(11,12)}$.

The Effect of Cross-linking of the Tooth Resin: Cross-linked acrylic teeth, Major-Dent (17.54 MPa), and Flori-Dent (17.26 MPa) have the lowest SBS when compared with other acrylic teeth types (Figures 4, and 5).

This result is supported by authors ${ }^{(20)}$ who reported that presence of a lesser amount of unlinked polymer chain in the cross-linked acrylic teeth compared to other types of acrylic teeth. Therefore, less unlinked polymer chains are available in the cross-linked teeth for the development of an interwoven polymer between the teeth and denture base resin, or the polymer chain networks in crosslinked polymer becomes too small for interpenetration of monomer from the denture base into the acrylic tooth; this results in poor bonding. While the other types of acrylic teeth, Super-Lux (19.52 MPa), Abdul-Nour (19.11 MPa) and Super-Cryl (19.05 MPa) in the present study showed higher SBS ${ }^{(9)}$.

Mode of Failure: This study revealed that adhesive failures are higher in untreated samples cured by water bath and microwave techniques (Tables 2, and 3) and Figure (6).

Table (2) Modes of failure for untreated and treated acrylic teeth types cured by water bath technique.

\begin{tabular}{|c|c|c|c|c|c|c|}
\hline \multirow[b]{2}{*}{$\begin{array}{c}\text { Surface } \\
\text { Treatment }\end{array}$} & \multirow{2}{*}{ Type of Teeth } & \multicolumn{4}{|c|}{ Modes of Failure } & \multirow{2}{*}{$\begin{array}{l}\text { Number of } \\
\text { Samples }\end{array}$} \\
\hline & & $\begin{array}{c}\text { Adhesive Clean } \\
\text { Interface \% }\end{array}$ & $\begin{array}{c}\text { Cohesive T } \\
(\%)\end{array}$ & $\begin{array}{c}\text { Cohesive A } \\
(\%)\end{array}$ & $\begin{array}{l}\text { Mixed, Adhesive } \\
\text { and Cohesive \% }\end{array}$ & \\
\hline \multirow[t]{5}{*}{ Untreated } & Abdul-Nour & 37.5 & 0 & 12.5 & 50 & 8 \\
\hline & Super-Cryl & 37.5 & 0 & 12.5 & 50 & 8 \\
\hline & Flori-Dent & 75 & 12.5 & 0 & 12.5 & 8 \\
\hline & Major-Dent & 62.5 & 0 & 0 & 37.5 & 8 \\
\hline & Super-Lux & 50 & 0 & 25 & 25 & 8 \\
\hline \multirow[t]{5}{*}{ Treated } & Abdul-Nour & 0 & 0 & 37.5 & 62.5 & 8 \\
\hline & Super-Cryl & 0 & 12.5 & 25 & 62.5 & 8 \\
\hline & Flori-Dent & 25 & 62.5 & 0 & 12.5 & 8 \\
\hline & Major-Dent & 12.5 & 50 & 0 & 37.5 & 8 \\
\hline & Super-Lux & 12.5 & 25 & 12.5 & 50 & 8 \\
\hline
\end{tabular}

Cohesive T: Cohesive within tooth structure. Cohesive A: within acrylic denture base material 
Table (3) Modes of failure for untreated and treated acrylic teeth types cured by microwave technique.

\begin{tabular}{clccccc}
\hline $\begin{array}{c}\text { Surface } \\
\text { Treatment }\end{array}$ & Type of Teeth & \multicolumn{4}{c}{ Modes of Failure } \\
\cline { 3 - 6 } & & $\begin{array}{c}\text { Adhesive } \\
\text { Clean Inter- } \\
\text { face (\%) }\end{array}$ & $\begin{array}{c}\text { Cohesive } \\
\text { T } \\
(\boldsymbol{\%})\end{array}$ & $\begin{array}{c}\text { Cohesive A } \\
(\boldsymbol{\%})\end{array}$ & $\begin{array}{c}\text { Mixed, Adhesive } \\
\text { and Cohesive } \\
(\%)\end{array}$ & $\begin{array}{c}\text { Number } \\
\text { of Sam- } \\
\text { ples }\end{array}$ \\
\hline Untreated & Abdul-Nour & 37.5 & 0 & 25 & 37.5 & 8 \\
& Super-Cryl & 12.5 & 12.5 & 12.5 & 62.5 & 8 \\
& Flori-Dent & 37.5 & 25 & 0 & 37.5 & 8 \\
& Major-Dent & 50 & 37.5 & 0 & 12.5 & 8 \\
& Super-Lux & 12.5 & 25 & 12.5 & 50 & 8 \\
\multirow{5}{*}{ Treated } & Abdul-Nour & 0 & 0 & 25 & 75 & 8 \\
& Super-Cryl & 0 & 12.5 & 37.5 & 50 & 8 \\
& Flori-Dent & 12.5 & 50 & 0 & 37.5 & 8 \\
& Major-Dent & 12.5 & 62.5 & 0 & 25 & 8 \\
& Super-Lux & 0 & 37.5 & 25 & 37.5 & 8
\end{tabular}

Cohesive T: Cohesive within tooth structure. Cohesive A: within acrylic denture base material

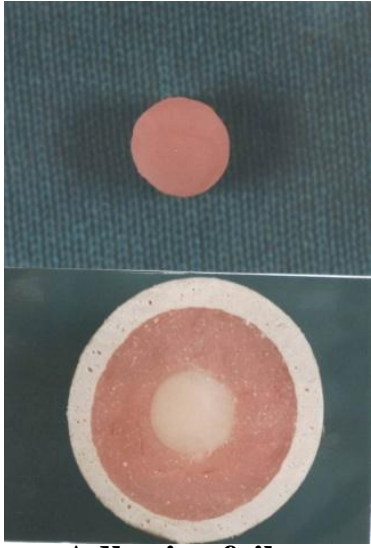

Adhesive failure

(adhesive

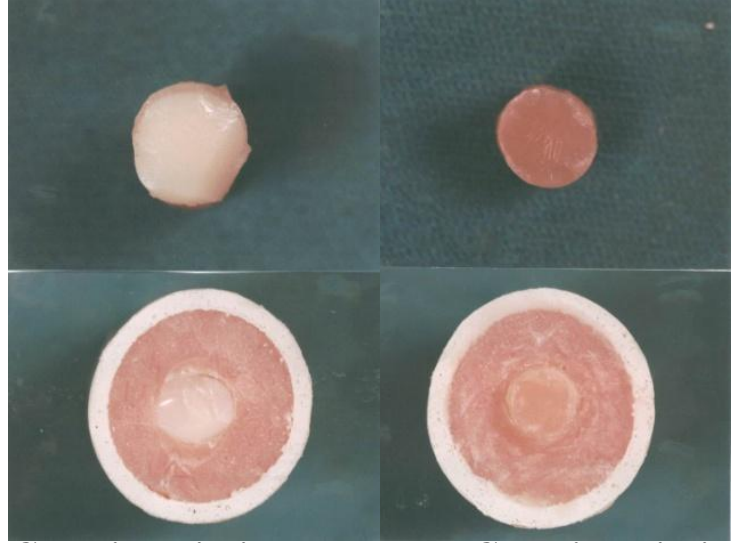

Cohesive within Tooth

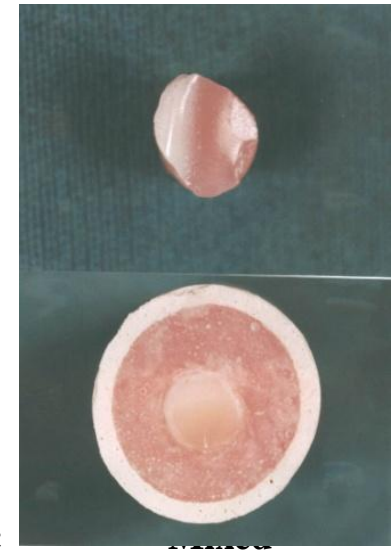

denture base.

Figure (6): Mode of Failures

The benefit of monomer surface treatment in improving the bond between denture teeth and denture base resin was evident. Acrylic teeth treated with monomer failed predominantly in the cohesive and mixed mode, different types of acrylic teeth produced various modes of failure.
Cross-linked acrylic teeth, Flori-Dent and Major-Dent, failed mostly in cohesive $\mathrm{T}$ (within tooth structure) as it is more brittle due to network structure ${ }^{(21)}$, while conventional acrylic teeth, Abdul-Nour and Super-Cryl, failed predominantly into mixed (adhesive and cohesive). Hard 
acrylic teeth, Super-Lux, modes of failure distributed into cohesive $\mathrm{T}$ (within tooth structure), cohesive A(within acrylic denture base material)., and mixed(adhesive and cohesive).

\section{CONCLUSIONS}

The shear bond strength of acrylic teeth to microwave cured denture base resin is significantly higher than that to conventionally water- bath cured denture base resin.

Cross- linked acrylic teeth (Flori-Dent and Major-Dent) show lowest shear bond strength comparing to other type of acrylic teeth.

Modes of failure are mostly adhesive in all types of untreated acrylic teeth, with monomer treatment, modes of failure are directed toward cohesive $\mathrm{T}$ (within tooth structure) for cross-linked acrylic teeth, mixed (adhesive and cohesive) for acrylic teeth, mixed, cohesive A and cohesive T for hard acrylic teeth.

\section{REFERENCES}

1- Schoonover IC, Fischer TE, Serio AF, Sweeney WT, Washington DC Bonding of plastic teeth to heat-cured denture base resins. J. Am. Dent. Assoc. 1952, 44: 285 287.

2- Vallittu PK, Lassila VP, Lappalainen R Evaluation of damage to removable dentures in two cities in Finland. Acta. Odontol. Scand. 1993. 51: 363-369.

3- Darbar UR, Huggett R , Harrison A Denture fracture - A survey. Br. Dent. J. 1994. 176: 342-345.

4- Morrow RM, Matvias FM, Windeler AS , Fuchs RJ Bonding of plastic teeth to two heat-curing denture base resins. J. Prosthet. Dent. 1978. 39(5): 565-568.

5- Catterlin RK, Plummer KD , Gulley ME Effect of tin foil substitute contamination on adhesion of resin denture tooth to its denture base. J. Prosthet. Dent. 1993. 69: 57-59.

6- Cunningham JL, Benington IC. A new technique for determining the denture tooth bond. J. Oral Rehabil. 1996. 23(3): 202-209.

7- Rupp NW, Bowen RL, Paffenbarger GC Bonding cold-curing denture base acrylic resin to acrylic resin teeth. J. Am. Dent. Assoc. 1971, 83: 601-606.
8- Clancy JMS , Boyer DB Comparative bond strengths of light-cured, heat-cured, and autopolymerizing denture resins to denture teeth. J. Prosthet. Dent. 1989. 61(4): 457-462.

9- Suzuki S, Sakoh M , Shiba A Adhesive bonding of denture base resins to plastic denture teeth. J. Biomed. Mater. Res. 1990.24(8): 1091-1103.

10- Szabo G, Csere T, Janko L, Szanto P Bonding strength and fracture resistance of artificial teeth in dental prostheses. $F_{O}$ gorv. Sz. 1995.88(8): 251-259 (Abstract).

11- Polyzois GL , Dahl JE Bonding of synthetic resin teeth to microwave or heat activated denture base resin. Eur. J. Prosthodont. Restor. Dent. 1993.2(1): 41-44.

12- Adeyemi AA, Lyons MF, and Cameron DA. The acrylic tooth-denture base bond: effect of mechanical preparation and surface treatment. Eur J Prosthodont Restor Dent. 2007;15(3):108-114.

13- Hasan RH. Denture teeth bond strength to heat water bath and microwave cured acrylic denture base materials: A comparative study. A Thesis of MSc. University of Mosul. 2002.

14- American Dental Association Specification (ADA). Guide to dental materials and devices $7^{\text {th }}$ ed. Chicago ADA . 1975.

15- Al-Azzawi SI Evaluation of some physical and mechanical properties of acrylic denture base materials cured by two different types of microwaves irradiation. M.Sc. Thesis, College of Dentistry, University of Baghdad. 1998

16- Buyukyilmaz S, Ruyter IE. The effects of polymerization temperature on the acrylic resin denture base-tooth bond. Int. J. Prosthodont. 1997.10(1): 49-54.

17- Chung RW, Clark RK, Darvell BW. The bonding of cold-cured acrylic resin to acrylic denture teeth. Aust. Dent. J.1995. 40(4): 241-245.

18- Chai J, Takahashi Y, Takahashi T , Habu $\mathrm{T}$. Bonding durability of conventional resinous denture teeth and highly crosslinked denture teeth to a pour-type denture base resin. Int. J. Prosthodont.2000. 13(2): 112-116.

19- Nishii M . Studies on the curing of denture base resins with microwave irradiation with particular reference to heat curing resins. J. Osaka Dent. Univ.1968. 2: 23-40. 
20- De Clerck JP . Microwave polymerization of acrylic resins used in dental prostheses. J. Prosthet. Dent. 1987.57(5): 650-658.

21- Saaverdra G, Valandro LF, Leite FPP, Amaral R, and Bottino MA. Bond strength of acrylic teeth to denture base resin after various surface conditioning methods before and after thermocycling. Int $\mathrm{J}$ Prosthodont.2007;20:199-201. 